\title{
The Impact of Environmental Regulation on Technological Innovation of Automobile Industry in China's Market- A Case by Tesla
}

\author{
Yue $\mathrm{Du}^{*}$
}

\author{
International economy and trade, China Agriculture University, China Beijing, \\ *Email: yue.du@ucdenver.edu
}

\begin{abstract}
With the negative externalities of the development of the automobile industry increasingly obvious, the government's environmental regulations will force the technological innovation of the automobile industry, the case of Tesla. The paper collects the R\&D investment data, environmental regulation intensity data, and sale revenues data of Tesla from 2012 to 2020 and tests the impact of environmental regulations on the automobile industry by constructing the econometric regression model in Excel. The results show that environmental regulations significantly positively impact technological innovation input (R\&D) and output (Sale) on Tesla. On this basis, the paper cuts forward the suggestions for the continuous development of automobile companies. The company should invest more in R\&D to make constant technological innovation with the help of the government's environmental regulations.
\end{abstract}

\section{Keywords: Environmental regulation, $R \& D$, Tesla, Automobile industry, Technological innovation}

\section{INTRODUCTION}

With the advancement of technology and innovation, there are still many great challenges to face in China's automobile industry, as some environmental issues. Also, there are great opportunities at the same time, ushered in the age of electrification and intelligence. In 2016, carbon dioxide $\left(\mathrm{CO}_{2}\right)$ concentration levels permanently exceeded the 400 parts per million thresholds, a level that many climate scientists believe will have a catastrophic impact on the environment. Worse, global $\mathrm{CO}_{2}$ emissions are increasing at an accelerating rate. Annual $\mathrm{CO}_{2}$ emissions have approximately doubled over the past 50 years to over 35 tons per year [1]. The path that the world currently is on is unsustainable and unwise. The 21 st century is a new era of rapid development of science and technology. It is a historic moment under the research and promotion of science and technology that new energy vehicles are supposed to be designed to protect the environment. The promotion of new energy vehicles aims to make full use of renewable energy, conserving energy, reducing emissions, and protecting non-renewable resources. The world cannot reduce $\mathrm{CO}_{2}$ emissions without addressing energy generation and consumption. And the world cannot address its energy habits without directly reducing emissions in the transportation and power sectors. To better cope with these problems, the automobile industry has carried out a new round of reform, and the era of the intelligent tram has come along with it. Among many automobile brands, Tesla is an important product under this era background. Tesla was founded in 2003 by a group of engineers who wanted to prove that people could also drive with the dream of environmental conservation and even did not need to compromise to drive electric- that electric vehicle could be better, quicker, and more fun to drive than gasoline cars. Tesla focuses on creating a complete power and transportation ecosystem from solar generation and energy storage to all-electric vehicles. Likewise, those environmental issues are more serious in China. According to the related research, climate change is reaching alarming levels-in large part due to emissions from burning fossil fuels for transportation and electricity generation. Therefore, introducing and developing new energy vehicles in China is of great significance to environmental protection. We believe the faster cars stop relying on fossil fuels and moves towards a zero-emissions future, the better. Therefore, the technological innovations of Tesla are of great significance in support of environmental conservation policies in China.

In recent years, China's total investment in reducing 
environmental pollution shows a trend of the increasing year by year, and the level of environmental regulation of the government is gradually strengthened, which shows a high degree of recognition. The total national investment in environmental pollution control increased by 5.5 times from 175 billion Yuan in 2003 to 953.9 billion Yuan in 2018. In the past five years alone, the central government spent more than 60 billion yuan (63.3 billion yuan) on air pollution control [2]. In the automobile industry, to achieve the ultimate goal, the government also pays adequate attention. In general, China's energy-saving and new energy vehicle development will be easy and difficult, divided into two steps: from 2011 to 2015, it will vigorously develop energy-saving vehicles. On the one hand, improve the fuel economy of traditional cars; On the other hand, it will realize the large-scale industrialization of ordinary hybrid electric vehicles. The total number of medium and heavy hybrid passenger cars is planned to exceed 1 million. As scheduled, from 2016 to 2020, the fuel economy of traditional vehicles would be raised to an internationally advanced level and would achieve a large-scale popularization of hybrid electric vehicles. Therefore, more efforts need to be done to achieve the goal, and electric vehicles could be the main force.

After more than ten years of construction of environmental regulations, China's environmental governance has gradually achieved results. Even though some waste emissions of transportation have been moderately controlled, the total waste gas emissions are still high. Therefore, China's environmental pollution problem is still relatively serious, and more environmental regulation policies are needed. Technological innovation is an important driving force and decisive factor of a country's long-term economic development and an effective way of environmental protection and economic development. Therefore, it is of great significance to study the impact of environmental regulation on the technological innovation of automobile industries. However, how to enhance the coordinated development of environmental regulation and automobile industries is the core issue of the high-quality development of automobile industries in China. With the development of science and technology, technological innovation has become the main way to develop resource-based industries and the environment. Many scholars at home and abroad hold different opinions on the relationship between environmental regulation and technological innovation. On the one hand, the Porter hypothesis is put forward by scholars represented by Porter, which holds that reasonable environmental regulation can promote the technological innovation of regulated enterprises and reduce environmental pollution [3]. On the other hand, new classical economics represented by Walley argues that environmental regulation can restrain the innovation activities of enterprises to a certain extent because environmental regulation increases the production cost of enterprises. Although the hypothesis made by Porter held that environmental regulation has a positive correlation with technological innovation, Walley's economic theory holds that environmental regulation restrains technological innovation of enterprises. Still, it needs to be tested by practical experiences [4].

In this research paper, we aim to address the following key issues: As for Tesla, whether the environmental regulation promotes or restrain the technological innovation of automobile industries? What extent of influence does the technological innovation exert on the market sales of Tesla? So, the paper's research question is the impact of environmental regulations on technological innovation in the Tesla market in China. In 2017, China gave certain support to new energy vehicles from the production, sales, and usage levels. This year, the national policy promotes the development of new energy vehicles with a favorable environment. And in 2018, there have been some related environmental regulations for the automobile industry. This paper will focus on the above question from two key perspectives. We apply Tesla's output and sales data in China market from 2012 to 2020 because Tesla entered the China market in 2012. Therefore, based on the existing research results, this paper studies the impact of environmental regulation on the technological innovation in the Tesla market in China and further proposes the collaborative policy of environmental regulation and technological innovation, which provides decision-making reference for Tesla to formulate market strategies to maximize its market value and sales revenues. The following part provides the literature review. The paper provides the establishment of model and data description. After that, it is the empirical test results and discussion; and the last part is the conclusion and strategy recommendations.

\section{LITERATURE REVIEW}

\subsection{Environmental regulations and monetary}

With the rapid development of the economy and society, people's environmental protection awareness is gradually enhanced [5]. However, the rapid growth of urban car ownership is still an important factor affecting air quality. The government has promulgated a series of acts such as the Law on the Prevention and Control of Air Pollution, which shows that the government attaches great importance to environmental protection. The implementation of the laws and regulations depends on the people's conscious actions. All sectors of society and relevant government departments are required to increase the publicity of environmental laws and regulations and use various media channels to raise people's awareness of environmental protection [6]. In 2018, China promulgated automobile emission 
standards three times, which played a positive role in controlling air pollution. To protect and improve the ecological environment, strengthen the prevention and control of air pollution, and promote sustainable economic and social control, China promulgated and implemented the Law on the Prevention and Control of Air Pollution. It has taken the prevention and control of air pollution to a new historical level. Article 9 of the Law stipulates that the state encourages and supports scientific research in the prevention and control of air pollution and encourages and supports the development and utilization of clean energy. It points out the direction for air pollution control and further development of environmental protection. The current national support for the consumer end of new energy vehicles can generally be summarized into three aspects: monetary subsidies, tax exemption, and license plate right of way [7].

\subsection{Policy on the car industry}

\subsubsection{Encourage regulation}

The automobile industry is one of the important pillar industries in China's national economic construction. It can simultaneously drive the development of nearly 100 upstream and downstream related industries. It has a vital role and significance for the development and stability of the socialist market economy. Currently, the international supply environment of petroleum resources is constantly changing and unstable, and the price fluctuates greatly. In addition, air pollution and environmental damage caused by traditional cars are becoming more and more serious. Therefore, the transformation and upgrading of the automobile industry are imperative. According to Keynes's theory of state intervention, industrial structure adjustment is bound to have some market failures. Therefore, appropriate government policies can protect the development of the new energy automobile industry, realize the effective allocation of resources and make up for the defects of market failures. Therefore, national and local governments have issued a series of monetary policies to encourage the start and development of the new energy vehicle industry and help it eliminate the path dependence effect of traditional energy vehicles. It is really helpful to a start-up new energy automobile company and beneficial for introducing and importing new energy vehicles. But the paper does not analyze how the impact of the environmental policies on the development of the new energy vehicle companies but exclusively focuses on some important economic supportive policies [8].

\subsubsection{Tax policies}

The automobile industry has a high degree of correlation and plays an important role in economic development. Therefore, the automobile industry has become one of the leading industries with high attention. To adapt to the development and change of social and economic situation, China has partially adjusted to the original tax system in recent years. By analyzing the influence of the adjustment of the tax system on the development of China's automobile industry, the following conclusions can be drawn: the influence of the adjustment of the tax system on the development of China's automobile industry is mostly positive [9].

\subsubsection{Environmental regulations}

Based on the dynamic econometric model, Fan empirically studies the impact of environmental policy and technological progress on environmental technology innovation in China's automobile industry from two aspects of product innovation and process innovation. The results showed that the environmental impact assessment system's environmental policy and the system of pollution within a time limit, R\&D investment and human capital of technological progress and environmental technology innovation. A long-term equilibrium relationship and the long-term equilibrium of product innovation short-term volatility impact are not big. Only as for the pollution within a time limit and $R \& D$ inputs of long-term equilibrium of process innovation, the effect of period fluctuation is significant. But they did more research on traditional automobiles, not new energy vehicles, which means they ignore the technological innovation in cars using the materials of electric and solar [10].

Environmental policy has a significant impact on the technological progress of enterprises. The research shows that the different environmental protection policies of the government can affect the technological innovation of enterprises. At present, the technological innovation of enterprises needs to be adjusted continuously according to the environmental protection subsidy policies formulated by the government to develop new technologies. That can better lead the development of enterprises and create a better environment to promote enterprises' technological innovation and realize the sustainable development of enterprises. In the case study of paper-making technology and paper products around Donating Lake, it is concluded that environmental regulation and technological innovation are mutually promoting and coordinating [11].

\subsection{Influential factors of technological innovation}

Gao systematically analyzes the impact of government subsidies on the technological innovation of the new energy vehicle industry. Government subsidies to the new energy vehicle industry, on the one hand, 
supply research and development, on the other hand, supply consumption. R\&D subsidy aims to directly promote the technological innovation behavior of enterprises; Consumer subsidies are designed to encourage technological innovation by expanding market demand. Therefore, the paper's outcome is mainly divided into two aspects: one is the impact of R\&D subsidies on technological innovation that is positive; the second is that the impact of consumer subsidies on technological innovation is positively related [12].

\subsection{The relationship of the technological innovation}

Taking 110 enterprises in Guangdong Province listed on the SME Board as samples, Tang and Chen divide technological innovation into technological innovation input and technological innovation output and study the relationship between technological innovation, marketing ability, matching technological innovation, and marketing ability enterprise performance. The results show that the input of technological innovation and marketing expenses improve the performance of enterprises in the market [13].

\subsection{The impact on the automobile industry}

The weak technological innovation ability of China's automobile industry has restricted the development of the industry [14]. Therefore, technological innovation is important if a brand wants to make further advancements in the automobile industry.

\subsection{Problems in new energy automobile industries}

Consumers are the final driving force of the new energy vehicle industry and an important factor affecting the sales of new energy vehicles. This paper compares and analyzes the basic characteristics of consumers and introduces the survey results from four aspects: personal attribute factor, product attribute factor, policy attribute factor, and social attribute factor. As for the product attribute factor, $64 \%$ and $54 \%$ of customers have the problem on the new energy vehicle technology is not mature, and the follow-up service is not perfect [15]. So, contributing to technological innovation can attract more customers by solving immature technology problems.

Based on the above, the existing literature presents that technological innovation is necessary for the new energy automobile industry and analyzes the impact of environmental regulations on technological innovation from different perspectives, which provides a reference for this study. Still, the existing literature focuses on the new energy automobile company- Tesla- to study environmental regulations on technological innovation. Due to the strategy to maximize the company's profit-keeping path with the government regulations for Tesla, it is of great practical significance to study the impact of the environmental regulations on the technological innovation of Tesla. Therefore, this paper puts forward two main hypotheses as follows:

H1: Environmental regulation is positively correlated with technological innovation and better sale performance of Tesla in China's market.

$\mathrm{H} 2$ : Environmental regulation is negatively correlated with technological innovation and worse sale performance of Tesla in China's market.

\section{METHOD}

\subsection{Research design}

Many people say that there are only two kinds of mobile phones globally, one is Apple mobile phone, and the other is the Android mobile phone. In the field of new energy vehicles, there are only two kinds of electric cars globally, one is Tesla electric cars, and the other is electric cars of other brands. It's no exaggeration to say that, like Apple, Tesla has set a standard in the industry that no other brand can match. Tesla has huge advantages in the following aspects: longer range, better power performance, autonomous driving technology, and high retention rate [16]. And Tesla has gone from strength to strength over the past decade to become the world's largest car company by market capitalization. Therefore, Tesla is the preferred representative to study the new energy vehicle industry.

Based on the research object, this paper collected data from Tesla company to demonstrate the impact of environmental regulations on technological innovation of the automobile industry. Specifically, the explained variable is technological innovation, measured by the investment of $\mathrm{R} \& \mathrm{D}$ and the sales revenues of Tesla in China's market. The first and the second model are both models of the impact of environmental regulations on the technological innovation of Tesla. The explanatory variable is the tensity of environmental regulations. And there are also some considerations like the effects of other policies introduced by the government in monetary subsidies and tax deduction subsidy policies.

The basic equations of measurement are as follows:

$$
\begin{aligned}
& R \& D_{t}=a_{1}+b_{1} E R I_{t}+e_{1} \\
& \text { Sale }_{t}=a_{2}+b_{2} E R I_{t}+e_{2}
\end{aligned}
$$

In the model, $t$ represents the time, $R \& D$ represents the investment of research and development funds, Sale represents the sales revenues of Tesla in China's market. ERI represents the intensity of environmental regulations, and " $e$ " represents the random interference item. 


\subsection{Variables}

\subsubsection{Explained variable}

Technological innovation can be measured by innovation input and innovation output. Considering the availability of data, the indicators of innovation input are mainly represented by the investment of $R \& D$ funds. The product sale revenues can measure the indicator of innovation output in China's market. Combining the literature review above, consumers are more willing to try the new type and new automobile technology [17]. So, the sales revenue is the most direct indicator to measure the output of technological innovation. Therefore, Then, R\&D investment is the foundation of technological innovation activities. And we assume that as soon as environmental policies are introduced, the company will have a quick response to increasing investment in the research and development department. The more R\&D investment, the higher the level of technological innovation is. Therefore, R\&D funds are an important indicator to measure the level of technological innovation.

\subsubsection{Explanatory variable}

Environmental regulation intensity (ERI): Referring to the methods used by previous scholars, this paper uses the cost index of expenditure or investment to measure the intensity of environmental regulation, which can better reflect the intensity of environmental regulations. The number of expenditures or investments increases with the increase of the intensity of environmental regulation. The stricter the environmental regulation, the more the expenditures on maintenance and supervision. Therefore, we use national fiscal expenditure on environmental protection from 2012 to 2020 to express the intensity of the environmental regulations.

\subsection{Data collection}

The "Sale" data used in this study comes from the China Association of Automobile Manufacturers. R\&D investment of Tesla comes from annual financial statements on Tesla's official website. And the environmental regulations introduced by the government are available in State Environmental Protection Administration. And how much does the government spends on environmental conservation is retrieved from the Prospective database. It has a large number of accurate and timely updated Chinese macro data and statistical charts. And some other governmental regulations are accepted from gov.cn.

\section{RESULTS}

Based on the data of Tesla, the paper makes diagram analysis with Excel combined with established model. Correlation analysis is used to quantify the degree of correlation between two variables. Correlation analysis measures the correlation coefficient and reflects how much the other variable will change when one variable changes. Correlation analysis can tell the linear relationship between two variables. So the paper tested the correlation coefficient among variables in Equation (1) and Equation (2), and did a simple linear regression. Results show a high correlation between the investment of R\&D and ERI with sales and ERI. As for Equation (1), the correlation index is 0.9093 with adjusted $\mathrm{R}$ square equaling 0.8021 in the $95 \%$ confidence level. The correlation index is positive, and its absolute value ranges from 0.8 and 1 , so variables $R \& D$ and ERI have highly linearly correlated ship and positively correlated [18]. With the higher level of intensity of environmental regulations, Tesla pays more attention to technological innovation and tends to make a higher investment in $R \& D$ to make more environmentally-friendly types. As for the second model. Equation (2), the correlation index is 0.7475 positively with adjusted $\mathrm{R}$ square 0.4958 in the $95 \%$ confidence level. The correlation index absolute value is between 0.5 and 0.8 , which means that variables sales and ERI are moderately linear and positively correlated. So we can find that the intensity of environmental regulations positively promotes the technological innovation output- sales revenues of Tesla in China's market. Then comparing with two models, we can find that $\mathrm{R}$ square and the correlation index if Equation (1) are higher than the one of Equation (2) so that environmental regulations intensity has a more linear relationship with technological innovations inputR\&D. In other words, ERI can exert a more significant influence on $R \& D$ than technological innovation output-Sale revenues.

Table 1. Descriptive statistic of variables

\begin{tabular}{cc}
\hline Regression statistic & \\
\hline Multiple R & 0.747537496 \\
R Square & 0.558812308 \\
Adjusted R Square & 0.495785495 \\
Standard error & 1.869223273 \\
Observed value & 9 \\
\hline
\end{tabular}


Table 2. Descriptive statistic of variables

\begin{tabular}{lllccrr}
\hline & Coefficients & Se & t Stat & P-value & Lower 95\% & Upper 95\% \\
\hline Intercept & -4.354328348 & 2.328888998 & -1.86970197 & 0.103723217 & -9.861275751 & 1.152619056 \\
ERI & 0.014093528 & 0.004733141 & 2.977627095 & 0.020583964 & 0.002901429 & 0.025285627 \\
\hline
\end{tabular}

Table 3. Descriptive statistic of variables

\begin{tabular}{ll}
\hline Regression statistic & \\
\hline Multiple R & 0.909312829 \\
R Square & 0.82684982 \\
Adjusted R Square & 0.80211408 \\
Standard error & 239.1150765 \\
Observed value & 9 \\
\hline
\end{tabular}

Table 4. Descriptive statistic of variables

\begin{tabular}{llccccc}
\hline & Coefficients & Se & t Stat & P-value & Lower 95\% & Upper 95\% \\
\hline Intercept & -734.6558497 & 297.9165083 & -2.465978988 & 0.043086103 & -1439.11645 & -30.19524922 \\
ERI & 3.500628708 & 0.605473563 & 5.781637583 & 0.000676117 & 2.068911237 & 4.932346179 \\
\hline
\end{tabular}

\section{DISCUSSION}

Comparing with the existing research, some people have proposed that those environmental policies positively correlated with the technological innovation of automobile industries. In contrast, some people believe that environmental regulations negatively correlated with technological innovation in automobile industries. But it is definitely certain that the traditional automobile industries have negative environmental externalities. So that the traditional automobile companies must promote technological innovation, and the introduction of new energy vehicle company Tesla is the right case. Tesla uses electricity to give customers an equally comfortable driving experience as fuel cars while Tesla follows up the related environmental regulations. With more and more strict environmental regulations come up, Tesla also needs to make enough technological innovation to follow up and go beyond in the world. Tesla is leading in the new energy automobile industry. When using the sample of Tesla, it is representative, and the study's conclusion can be prevailing and persuasive. Besides, the adoption of new energy vehicles is the general trend of the market, so it is of great significance to research and analyze the new energy industry caused by Tesla and the Tesla company itself. For Tesla, to keep up with the constant demand of the market and maximize its profit constantly, it should pay enough attention to technological innovation and invest more in R\&D with the help of government policies. Government policies are like the powerful spray of the enterprise boat, while technological innovation is the powerful motor power. Only when the two meet each other can the enterprise boat develop into a giant ship and continue to sail steadily in the ocean of the market.

\section{CONCLUSION}

Using Excel to do a linear regression model test with Tesla data from 2012 to 2020 , we tested the hypothesis that environmental regulation is significantly positively correlated with technological innovation and with better sale performance of Tesla in China's market. However, as for the limitations of this study, there should be exceptions to the rule. We concluded the big company Tesla. Some small and start-up new energy automobile companies may not adapt to make more technological innovation with the background of more environmental regulations because of lack of adequate $R \& D$ funds and investments. Thus, if tending to know the whole automobile industry, more companies have to be chosen. In that way, the conclusion can be more general and considers the variable of the company type.

\section{REFERENCES}

[1] Li Zhenyu, Li Chao, and Liao Kai." The development trend of low-carbon car traffic and its emission reduction potential analysis." China Energy 038.0092016, 40-44. DOI: http: // doi.org/ 10.3969/j.issn.1003-2355.2016.09.009

[2] $\mathrm{Hu}$ Lixin, Han Linlin." The Impact of Local Government Environmental Action on Environmental Investment of Listed Companies." Journal of Accounting, 000.0172016, 10-13. DOI: http://doi.org/10.3969/j.issn.1004-5937.2019.17.00 3

[3] Porter, M.E.; Van Der Linde, C. Toward a New 
Conception of the Environment-Competitiveness Relationship.J. Econ. Perspect. 1995, 9, 97118.DOI: http://doi.org/10.1257/jep.9.4.97

[4] Walley, N.W. It's Not Easy Been Green; Welford, R., Starkey, R., Eds.; The Earth Scan in Business and the Environment: London, UK, 1996; pp. 334-337.

[5] Xiong Xuegang." Developing Economy and Protecting the Environment (I): Environmental Awareness in the New Century." China Environmental Protection Industry 000.005(1997):14-15. DOI: http://doi.org/ CNKI:SUN:ZHBY.0.1997-06-010

[6] Zhang Xiaoyu." Analysis of the Impact of Macroeconomic Environment on the Automobile Industry." 2009 International Forum on China Automobile Industry Development, China Automotive Engineering Society; China Association of Automobile Manufacturers, 2009.

[7] Wang Hui. Research on Fiscal and Tax Policies to Promote the Development of China's New Energy Vehicle Industry. Diss. Jiangxi University of Finance and Economics, 2010. DOI: http://doi.org/10.7666/d.y1845216

[8] Zheng Guihua, Li Holi, and Pan Bo." The Impact of Financial Subsidy and Tax Benefit on R\&D Investment of New Energy Vehicle Industry." Journal of Finance \& Economics, V.40; No. $220.04 \quad$ 2019 : 103-108. DOI: http://doi/org/CNKI:SUN:CLSJ.0.2019-04-015

[9] Li Shaoping, Dai Xanjun, Liu Guangming." A study on the relationship between tax incentives and financial subsidies and the development of new energy vehicle companies." Resources Development and Market 34.11,2018:1552-1557. DOI:http://doi.org/10.3969/j.issn.1005-8141.2018.1 1.012

[10] Zhen Zijian." Realizing the "Three Vertical and Three Horizontal" Key Technology Breakthrough and Technological Innovation Drives the Formation of China's New Energy Vehicle Strategic Emerging Industry." China Science and Technology Wealth 000.007, 2011: 26-28. DOI: http: doi.org/ 10.3969/j.issn.1671-461X.2011.07.011

[11] Zhao XiKang." The Impact of Environmental Policy on Technological Innovation." Journal of China University of Geosciences (Social Sciences Edition) 4.1, 2004: 24-28. DOI:http://doi.org/10.3969/j.issn.1671-0169.2004. 01.006

[12] Gao Qian, Fan Ming, and Du Jianguo." A Study on the Evolution of the Impact of Government
Subsidy on New Energy Vehicle Enterprises." Science and Technology Management Research 034.011,2014:75-79.

DOI:

CNKI:SUN:KJGL.0.2014-11-017

[13] Tang Qing, Chen Haiyan." Research on the Impact of Technological Innovation and Marketing Capability on Firm Performance." Journal of Science and Technology Management V.35; No. 331.009, 2015 DOI:http://doi/org/110-114. DOI: 10.3969/j.issn.1000-7695.2015.09.021

[14] Fan Qunlin, Shao Yunfei, and Tang Xiaowo." An Empirical Study on the Influencing Factors of Environmental Technology Innovation in China's Automobile Industry." Journal of Management 9.9,2012:1323. DOI: http://doi.org/ 10.3969/j.issn.1002-2104.2011.06.006

[15] Shao Jihong, Xin Mingliang." Analysis of Factors Affecting Consumers' Purchase of New Energy Vehicles." Enterprise Review 000.002(2012):83-86. DOI: CNKI: SUN:QYDB.0.2012-02-061

[16] Kevin Bliss." Tesla's Technological Advantage." Science and Technology Entrepreneurship 000.001,2014:44-45.

DOI: http:doi.org/10.3969/j.issn.1671-3265.2014.01.023

[17] Kiso, T. Environmental Policy and Induced Technological Change: Evidence from Automobile Fuel Economy Regulations. Environ Resource Econ 74, 785-810, 2019. DOI: https://doi.org/10.1007/s10640-019-00347-6

[18] Wang Haiyan, Yang Fangting, and Liu Lu." Comparison and Application of Standardization Coefficient and Partial Correlation Coefficient." Journal of Quantitative and Technical Economics 23.9,2006:150-155.

DOI: http:doi.org/10.3969/j.issn.1000-3894.2006.09.016 